\title{
QUANDO AS IMAGENS NOS FAZEM PENSAR O REAL
}

\section{Antonio de Medeiros}

\section{Resumo}

A partir da leitura de Quando as imagens tomam posição de Didi-Huberman este artigo busca investigar o uso potente das imagens nas artes, em especial em uma exposição fotográfica de Alfredo Jaart, em uma fotografia polêmica de Kevin Carter e no filme $O$ abutre de Dan Gilroy, em todos esses exemplos o enfoque é o seu papel de ativador do questionamento e do posicionamento do público.

\section{Palavras-chave}

Didi- Huberman. Kriegsfibel. O uso potente das imagens.

A partir de 1933, com a ascensão do nazismo, Bertolt Brecht inicia um longo período de exílio por vários países europeus e pelos Estados Unidos, que só findaria em 1948 com o seu retorno à Alemanha. Durante parte desse tempo, Brecht trabalhou em uma espécie de atlas fotográfico, o Kriegsfibel (ou Abecedário da Guerra), um exemplo de montagem que consistia em recortes de imagens da guerra de revistas da época com suas legendas originais e o acréscimo de pequenas epigramas (composições poéticas) do próprio Brecht.

Uma dessas composições, a placa de número 47, é uma imagem de janeiro de 1943. O cenário é uma praia, há um soldado em primeiro plano, de costas para a câmera e com uma arma na mão direita, há ainda alguns corpos estirados na areia. Não ter o rosto deste combatente, que sabemos ser americano pela legenda, não o individualiza, ao contrário, ele se torna um símbolo de todos os combatentes americanos. $\mathrm{O}$ fato dele estar em pé e em primeiro plano constrói uma imagem de grandeza e de poder que muito se assemelha aos famosos cartazes de filmes americanos de faroeste.

A legenda original logo abaixo da foto tem a seguinte descrição: "Um soldado americano olha para um soldado japonês que acabara de ser forçado a matar. O japonês tinha se escondido em uma embarcação e disparou contra as tropas norte-americanas." Esse trecho já constrói uma narrativa com a clara visão de uma propaganda de guerra, na qual o combatente americano se apresenta como um herói que agiu em legítima defesa. 
Logo abaixo, no espaço em preto, segue o trecho do poema de Brecht: "Tinha ficado vermelha de sangue uma praia. Que não pertencia a nenhum dos dois. Eles foram forçados dizem eles, a matar. Eu acredito, eu acredito, mas pergunta-se: Por quem?”.

De forma dialética, a construção poética de Brecht se relaciona (dialoga) por meio do recurso da montagem com a legenda original e com a foto, propondo um momento de reflexão em quem observa o trabalho.

Didi-Huberman (2008) em Quando as imagens tomam posição afirma que esse efeito dialético torna as três partes da obra (foto, legenda original e epigrama) interdependentes e levanta uma dúvida, apresenta um questionamento que retira o público da passividade: é louvável a luta contra o fascismo, mas há um interesse imperialista por trás dessa ação e os soldados são manipulados como ferramentas de guerra para interesses maiores e alheios a eles.

A posição de exilado permitiu a Brecht observar a guerra sob um ponto de vista privilegiado. Seu olhar de fora do conflito lhe permitia uma visão atenta e crítica dos eventos e sua experiência como médico durante a Primeira Guerra Mundial lhe possibilitava também saber como o confronto se organizava internamente. Em seu trabalho nos postos médicos, Brecht percebeu o quanto os feridos eram tratados de modo rápido para que voltassem logo a lutar nos conflitos. A coexistência dessas duas posições pela qual Brecht podia observar a guerra encontra possíveis aproximações com as características de distanciamento e de ator brechtiano:

\footnotetext{
Não é só o ver, mas também pensar a posição pela qual se olha. Eis, dentro da arte, uma violência revolucionária, utópica, de estranhar formas e sobreviver a elas como espectador, especialmente, ao embutir no conceito de espectador a característica do ator brechtiano que não se metamorfoseia por completo com sua personagem, mas sim exige no que pressupõe metamorfoses incompletas entre si e o que se representa - no caso do espectador, o que se recria ao olhar (SOUSA e PEREIRA, 2017, p.104).
}

Outra técnica de montagem que pode ser trazida em questão para se discutir a potencialidade das imagens como nova modelagem do pensamento, além da linguagem, está no "Atla Mnemosyne" de Aby Warburg. Por meio da compilação de inúmeras imagens (reproduções de pinturas, artes gráficas, fotografias, anúncios publicitários, dentre outras miscelâneas) compunham imensos painéis de forro preto. Essa compilação 
de imagens caóticas engendra, pela parte do espectador dessa obra, a possibilidade de criação de pontes entre tempos históricos distintos e associações inéditas e reveladoras.

Essa técnica de Warburg é uma ferramenta para se evitar a armadilha tão sedutora da historicidade, do pensamento linear, da noção de que o passar do tempo leva necessariamente ao progresso e de que todos os fatos são regidos por uma lógica primeira de causa e consequência:

\begin{abstract}
A montagem será precisamente uma das respostas fundamentais a esse problema de construção da historicidade, a montagem escapa às teleologias, torna sensíveis as sobrevivências, os anacronismos, os encontros de temporalidades contraditórias que afetam cada objeto, cada acontecimento, cada pessoa, cada gesto. Então, o historiador renuncia a contar "uma história" mas, ao fazê-lo, consegue mostrar que a história não é senão todas as complexidades do tempo, todos os estratos da arqueologia, todos os pontilhados do destino (DIDI-HUBERMAN, 2012, p.211).
\end{abstract}

Essas técnicas de montagem auxiliam numa percepção mais ampla do que é a imagem, cujo entendimento se amplia como uma abertura tal como uma porta e não como uma superfície.

Há uma certa inserção do fator acaso nesse trabalho de Warburg, o que nos permite uma associação, por exemplo, com o Dadaísmo que se propunha a compor um poema a partir de palavras recortadas do jornal e sorteadas.

O Dadaísmo, movimento artístico e cultural do início do século XX, incentivava uma reflexão, geralmente bem-humorada ou irônica, do "status quo", propondo uma nova forma de olhar o mundo ao redor, seja deslocando os objetos para novas perspectivas, como o "ready made" de Duchamp ou construindo poemas aleatórios. O caos, então, era aceito como uma das possibilidades de criação artística e contestação política ao consumismo e a falta de sentido do mundo.

Jacques Rancière (2012) afirma no capítulo $A$ imagem intolerável de $O$ espectador emancipado que assim como a retórica e a poética clássicas no ensinam que há imagens na linguagem, há também figuras de retórica e de poética no visível. Desse modo, as imagens permitem associações com outras imagens, aberturas para um sentido figurado e metafórico e para características da persuasão. Logo, assim como se lê um texto, as imagens também passam por um processo de leitura, de decodificação, de associação e por fim assimilação. 
Saber ler uma imagem é algo que exige do espectador dos dias de hoje um esforço de parar por um momento e observar o que lhe é mostrado, da mesma forma que a leitura de um poema exige um outro usufruto do tempo para decifrar o seu enigma, entender o que nele nos desconcerta e compreender as suas metáforas:

"Saber olhar uma imagem seria, de certo modo, tornar-se capaz de discernir o lugar onde arde, o lugar onde sua eventual beleza reserva um espaço a um sinal secreto, uma crise não apaziguada, um sintoma." (Didi-Huberman, 2012, p.214).

A correta observação da imagem pede esse esforço de quem a observa:

"Uma imagem bem olhada seria, portanto, uma imagem que soube desconcertar, depois renovar nossa linguagem, e portanto nosso pensamento." (Didi-Huberman, 2012, p.215)

Didi-Huberman (2012) nos alerta para o aumento da força da imposição das imagens em todos os aspectos de nossas vidas: "nunca a imagem se impôs com tanta força em nosso universo estético, técnico, cotidiano, político, histórico. Nunca mostrou verdades tão cruas.”.

No entanto, Rancière, (2012), alerta que as imagens intoleráveis, como a montagem de uma criança vietnamita morta nos braços do pai e dentro de um apartamento luxuoso não causou, necessariamente, um efeito de consciência política ou culpa e autocrítica nas pessoas que viram essa imagem. Muitas vezes o efeito conseguido era o de aversão a esse tipo de imagem ou de culpar terceiros por esses acontecimentos. Logo, não é chocando as pessoas que se conseguirá retirá-las da passividade de meros consumidores de imagens.

Outro argumento contestado por Rancière é o de que a profusão de imagens na atualidade é a responsável por sua banalização. Para ele, essas imagens são, cuidadosamente, escolhidas e manipuladas por especialistas, jornalistas e outros formadores de opinião que nos explicam as imagens e nos dizem o que devemos pensar acerca delas. O que falta a essa imagens é a individualização. A despersonalização dos indivíduos ocorre pela omissão de seus nomes, pela ausência dessas pessoas de terem a palavra. A narrativa delas é construída (já pré-fabricada e bastante editada) para ilustrar suas imagens.

Portanto, não é a quantidade de imagens a responsável por nos tornar insensíveis aos massacres e ao sofrimento, mas sim a ausência da singularização dos corpos e das 
narrativas que as fotos apresentam, pois são: "corpos que são objeto de palavra sem terem a palavra", frisa Rancière (2012).

Alfredo Jaart em um vídeo para o Louisina Channel afirma que as imagens não são inocentes e que elas representam um conceito ideológico de mundo. Pode-se associar o que disse Jaart com o posicionamento de Rancière (2012) ainda em $O$ espectador emancipado: "Uma imagem nunca está sozinha. Pertence a um dispositivo de visibilidade que regula o estatuto dos corpos representados e o tipo de atenção que merecem.”.

Ainda tendo como exemplo a obra do artista chileno Jaar, nesse mesmo vídeo para o Louisina Channel, é exibido um de seus trabalhos que consiste na exposição em ordem cronológica de 17 capas da Newsweek, um das mais importantes revistas semanais norte-americanas, durante o período de início do conhecimento mundial do massacre em Ruanda. Apenas na décima-sétima capa, ou seja, depois de 17 semanas do início do massacre foi que o assunto mereceu uma capa dessa revista.

Destaca-se nisso o questionamento levantado por Ranciére que nos ajuda a formular hipóteses para essa tardia cobertura de tão grave massacre. Jaar questiona a indiferença com que isso foi tratado, o que nos leva a refletir que algumas vidas, alguns corpos, notadamente de negros e de populações de países pobres são considerados pela mídia global de menor importância. Segundo Rancière (2012) “a questão é saber o tipo de atenção que este ou aquele dispositivo provoca".

Nessa obra além das capas, Jaar ainda se utilizou de um recurso de montagem, pois embaixo de cada capa, ele inseriu legendas com os números de mortos crescentes a cada semana. Há um contraste entre as capas e os dados das legendas, e essa construção artística pode despertar uma conscientização no espectador fazendo-o refletir sobre o papel da mídia.

Outra referência a ser destacada em $A$ imagem intolerável é a impactante história do fotógrafo sul-africano Kevin Carter que registrou a imagem de uma criança faminta sendo observada por um abutre no Sudão do Sul. Karter recebeu o prêmio Pulitzer por essa foto, no entanto, foi bastante criticado pela opinião pública e pela imprensa, sendo até mesmo chamado do segundo abutre por não ter ajudado a criança e, por ter também, de certa forma, feito uso da situação miserável e vulnerável da criança para o seu próprio interesse. Essas pesadas críticas tiveram forte influência na sua decisão de se suicidar. 
Com pontos em comum com esse caso dramático, o filme $O$ abutre de Dan Gilroy traz à tona a discussão do uso de imagens violentas e do sofrimento alheio para atrair a audiência e despertar a curiosidade. A história é a de um jovem que registra imagens de crimes e acidentes para vendê-los para o jornalismo criminal de Los Angeles. No caso em questão, o abutre é o próprio fotógrafo, um sujeito que tira seu sustento do registro da desgraça dos outros.

Outro ponto em destaque desse filme é revelar que o público consumidor desse tipo de imagem também pode ser considerado como um tipo de abutre. Há todo um sistema de retroalimentação interessado na exploração da morte e da desgraça alheia. É uma característica humana essa curiosidade pelo mórbido, haja vista os engarrafamentos nas estradas quando acontece um acidente.

Retomando a ideia da "imagem intolerável", Rancière (2012) apresenta alternativas para uma outra política do sensível, ou seja, por uma outra forma de compreender e trabalhar com as imagens, na qual ocorra um movimento de estranhamento ou de curiosidade, e que: "produza um deslocamento do desgastado afeto da indignação para um afeto mais discreto, um afeto de efeito indeterminado, a curiosidade, o desejo de ver de mais de perto."

Há algo na imagem de potente, uma imagem que arde se quisermos retomar a expressão de Didi-Huberman em Quando as imagens tocam o real, que faz com que o público não saiba já de antemão por alguém o que está vendo, como numa visita-guiada a um museu em que a guia apressada, antes que o público assimile e crie suas próprias impressões, lhe informa e direciona o olhar do que está sendo visto.

O uso potente da imagem, segundo Rancière, é aquele no qual nossos olhos não sabem de antemão o que estão vendo e o nosso pensamento não sabe o que fazer com o que vemos. Isso nos leva a uma curiosidade, a um movimento de aproximação, "é preciso acercar o rosto à cinza" (Didi-Hubeman, 2012, p.216) e a um movimento de afastamento da imagem.

São as imagens que conseguem nos causar esses efeitos que mudam nosso olhar e a paisagem do possível.

\section{Referências Bibliográficas}


DIDI-HUBERMAN, Georges. Quando as imagens tocam o real (tradução de Patrícia Carmelho e Vera Casa Nova). In: Revista Pós. Escola de Belas Artes. Universidade Federal de Minas Gerais. Vol 2, ed.nr.4, 2012.

Quando as imagens tomam posição - O olho da história, I. (tradução de Cleonice Paes Barreto Mourão) Minas Gerais: UFMG, $1^{\text {a }}$ ed., 2017.

LEITÃO, João Cristóvão. Montagem narrativa não dramática ou quando a montagem toma posição. Lisboa, 110 p. (Dissertação de Mestrado - Especialização em Audiovisuais). Faculdade de Belas-Artes, Universidade de Lisboa.

RANCIÈRE, Jacques. O espetador emancipado. São Paulo: WMF Martins Fontes, 2012.

SOUSA, Edson Luiz André de: PEREIRA, Márcio Fransen. "Bertolt Brecht-Exílio, Imagem e Utopia". Porto Arte: Revista de Artes Visuais. Porto Alegre: PPGAVUFRGS, v.22, n. 36, p. 93-113, 2017.

\title{
Arquivos da Internet
}

Alfredo Jaar: imagens are NOT innocent. Louisiana Channel. Produção: Christian Lund and Kamilla Bruus, ano 2013. Duração: 11 minutos. Disponível em: https://vimeo.com/164688358. Acesso em: julho de 2018.

\section{WHEN IMAGES MAKE US THINK THE REAL}

\begin{abstract}
This article begins with a study about Didi-Huberman's book Quando as imagens tomam posição in order to investigate the powerful use of images on arts and its influence on the attitudes and behaviors of the audience. It also refers to Alfredo Jaart, Kevin Carter e Dan Gilroy's works.
\end{abstract}

\section{Keywords}

Didi- Huberman. Kriegsfibel. Powerful use of images. 